\title{
CULTURAS LEGITIMAS: LA TRADUCCIÓN DE HISTORIETAS LATINOAMERICANAS EN BRASIL
}

\section{LEGITIMATE CULTURES: THE TRANSLATION OF LATIN AMERICAN COMICS IN BRAZIL}

\section{CULTURAS LEGÍTIMAS: A TRADUÇÃO DE HISTÓRIAS EM QUADRINHOS LATINO-AMERICANAS NO BRASIL}

\section{Barbara Zocal ${ }^{*}$}

\section{RESUMEN}

En este artículo, realizamos un sobrevuelo sobre cuestiones sociales de las últimas décadas con respecto al lugar de la traducción de la lengua española en Brasil. Además, tratamos de presentar la relevancia de la traducción en el mercado editorial de las historietas, sobre todo de las latinoamericanas traducidas al portugués, con el objetivo de observar las regularidades del mercado editorial de las historietas traducidas. Al final, presentamos un estudio de caso de la traducción brasilera, intitulada Sendero Luminoso (Editorial Veneta, 2016), de las novelas gráficas peruanas Rupay. Historias gráficas de la violencia política en el Perú (1980-1984), de Luis Rossell, Alfredo Villar y Jesús Cossio (Editorial Contracultura, 2008), y Barbarie. Comics sobre Violencia Política en el Perú, 1985-1990, de Jesús Cossio (Editorial Contracultura, 2010).

Palabras-clave: traducción, historietas, Latinoamérica.

\section{ABSTRACT}

In this paper, we conduct an overview of the presence and place of Spanish translation in Brazil during the 21st century. Beyond this, we intend to show the relevance of and regularities within the editorial market of comic books, concentrating on Latin-American comics translated to Portuguese. In order to illustrate both, we present a case study of Sendero Luminoso (Editorial Veneta, 2016), the Brazilian Translation of the Peruvian graphic novels entitled Rupay. Historias gráficas de la violencia política en el Perú (19801984), by Luis Rossell, Alfredo Villar and Jesús Cossio (Editorial Contracultura, 2008), and Barbarie. Comics sobre Violencia Política en el Perú, 1985-1990, by Jesús Cossio (Editorial Contracultura, 2010).

Keywords: translation studies, comics, Latin America.

\section{RESUMO}

Neste artigo, realizamos um sobrevoo sobre questões sociais das últimas décadas com respeito ao lugar da tradução da língua espanhola no Brasil. Além disso, procuramos mostrar

\footnotetext{
* Universidade de São Paulo, São Paulo (SP), Brasil. barbara.zocal@gmail.com 
a relevância da tradução no mercado editorial de quadrinhos, especialmente dos latinoamericanos traduzidos para o português, a fim de observar as regularidades desse mercado editorial traduzido. Ao final, apresentamos um estudo de caso da tradução brasileira Sendero Luminoso (Editorial Veneta, 2016) das novelas gráficas peruanas Rupay. Historias gráficas de la violencia política en el Perú (1980-1984), de Luis Rossell, Alfredo Villar e Jesús Cossio (Editorial Contracultura, 2008), e Barbarie. Comics sobre Violencia Política en el Perú, 1985-1990, de Jesús Cossio (Editorial Contracultura, 2010).

Palavras-chave: tradução, história em quadrinhos, América Latina.

La traducción, oficio y acto complejo, involucra cultura, lenguas, territorios, afán de comunicación, historia y relaciona, sobre todo, agentes (seres humanos que se socializan en interacción), objetividades y subjetividades. Aunque haya herramientas que faciliten e instrumentalicen el trabajo del traductor, tales como las translation machines (TM), aun así habrá agentes involucrados en desarrollarlas. Por lo tanto, es fundamental que se lleven a cabo y se fortalezcan investigaciones sobre traducciones, en el territorio fructífero para tales desarrollos, que consideramos sea el ámbito de la Traductología, o como se conviene denominar en Brasil Estudos da Tradução (Estudios de la Traducción), una disciplina implementada desde los años 80 en el país. Sin embargo, por pensar que todos los movimientos pertenecientes al acto de la traducción son mediados por agentes con fines de comunicación, lo que presupone un quehacer dialéctico entre todas esas prácticas y teorías, nos conviene conducir estas investigaciones en el abordaje sociológico, en desarrollo desde los años 2000 en las investigaciones eurocéntricas y desde hace poco más de diez años en Brasil.

Cuando se trata de las traducciones en América Latina, de investigaciones en Estudos da Tradução acerca del par lingüísticos español $<>$ portugués, de las historietas (o cómics) publicadas y traducidas en los países de América Latina, la cartografía queda mucho más compleja, por la carencia de investigaciones, por las escasas inversiones disponibles para tales investigaciones, porque como brasileños miramos hacia un norte, en una búsqueda de respuestas y modelos para aplicar en lo cotidiano y en los saberes epistemológicos, que no lograremos encontrar si no nos miramos hacia nosotros mismos y hacia el alrededor más cercano.

En este artículo, realizamos un sobrevuelo sobre cuestiones sociales de las últimas décadas con respecto al lugar de la traducción de la lengua española en Brasil. Además, tratamos de presentar la relevancia de la traducción en el mercado editorial de las historietas, sobre todo de las latinoamericanas traducidas al portugués, con el objetivo de observar las regularidades del mercado editorial de las historietas traducidas. Al final, presentamos un estudio de caso de la traducción brasilera de las novelas gráficas peruanas Rupay. Historias gráficas de la violencia política en el Perú (1980- 
1984), de Luis Rossell, Alfredo Villar y Jesús Cossio (Editorial Contracultura, 2008), y Barbarie. Comics sobre Violencia Política en el Perú, 1985-1990, de Jesús Cossio (Editorial Contracultura, 2010), intitulada Sendero Luminoso (Editorial Veneta, 2016) y traducida por Rogério de Campos y Barbara Zocal.

\section{LENGUAS Y TERRITORIOS: BREVES APUNTES SOBRE LA TRADUCCIÓN ESPAÑOL > PORTUGUÉS EN BRASIL}

La relación entre la traducción del par lingüístico español $>$ portugués es compleja, sobre todo porque presupone distintos estereotipos, fomentados, en mayor medida, por las formas de clasificación del status de esta práctica por los órganos gubernamentales (los que rigen las normas), que reverbera en el ideario del sentido común de los brasileros, de los que contratan traductores, de los estudiantes de español, etc. Si bien se cree en una proyección de éxito y amplitud del mercado de trabajo en el área de traducción de lengua española, idea recurrente entre estudiantes de grado de Traducción, debido a la integración de los países pertenecientes al MERCOSUR (SIMÃO, 2011), la realidad de los acuerdos internacionales promulga lo contrario.

En 2011, señalaba Simão que el status de la lengua española en el ámbito de la traducción en Brasil no le parecía tan prominente como en el ámbito de la enseñanza. Sin embargo, lo que observamos en la actualidad, bajo la aprobación de la Base Nacional Común Curricular (BNCC) el 15 de diciembre de 2017 -en la instancia del Conselho Nacional de Educação (CNE) - es que la enseñanza de español lengua extranjera ha sido relegada a segundo plano, como una asignatura electiva en el caso de las escuelas que deseen ofrecerla en sus currículos, al paso que el inglés se mantuvo como lengua de enseñanza obligatoria.

La legitimación de la traducción en el ámbito profesional, a su vez, enfrenta algunas trabas. En 2006, entró en vigor el decreto n ${ }^{\circ} 5.851$ promulgando el "Acuerdo sobre Exención de Traducción de Documentos Administrativos para Efectos de Inmigración entre los Estados Partes del MERCOSUR", firmado el 15 de diciembre de 2000, en la ciudad de Florianópolis, en el que a cualquiera de los Estados Partes se le dispensaba, en trámites administrativos migratorios (referentes a solicitud de visa, renovación del plazo de estadía y concesión de permanencia), la exigencia de traducción de documentos tales como pasaporte, cédula de identidad, testimonios de partidas o certificados de nacimiento y matrimonio, y certificados de ausencia de antecedentes penales. Según Simão (2011), aunque se vea y se justifique esta dispensa como un gesto de proximidad entre Brasil y los países Estados Partes del 
MERCOSUR, el acuerdo causó perjuicios directos a los traductores públicos (o jurados) brasileros de lengua española; $y$, además,

(...) tal medida actúa simbólica y objetivamente en el no reconocimiento del 'carácter extranjero' del idioma español para los hablantes de portugués y viceversa, por sacar el prestigio y, en consecuencia, disminuir el status del idioma en el ámbito de la traducción, por traer a cuento también la cuestión de supuesta facilidad de comprensión de la lengua española por los brasileros, estereotipo bastante difundido en Brasil, sobre todo en las regiones sur y sureste del país. ${ }^{1}$ (SIMÃO, 2011, p. 54).

Sin embargo, hay que tener en cuenta que el MERCOSUR es uno de los grupos que agrega Brasil a los otros países hispanohablantes y las restricciones a la legitimidad de la traducción del español al portugués ocurren en otras esferas. En el "Tratado Constitutivo de la Unión de Naciones Suramericanas" de la Unión de Naciones Suramericanas (UNASUR) y sus protocolos adicionales, por ejemplo, se perciben algunas revelaciones, tales como la distinción entre los 'idiomas oficiales' y los 'idiomas de trabajo'.

El primer tratado, firmado el 23 de mayo de 2008, en la ciudad de Brasilia (Brasil), y en vigor desde el 11 de marzo de 2011, el Artículo 10, intitulado 'La Secretaría General', puntúa una perspectiva integradora, aunque no se mencione ningún comentario sobre la necesidad de traducciones oficiales y cómo desarrollar esta práctica: "En la selección de los funcionarios de la Secretaría General se garantizará una representación equitativa entre los Estados Miembros, tomando en cuenta, en lo posible, criterios de género, idiomas, étnicos y otros." (TRATADO CONSTITUTIVO, 2011, pp. 18-19); y, además, prevé cuatro idiomas oficiales en el Artículo 23, intitulado 'Idiomas': "Los idiomas oficiales de la Unión de Naciones Suramericanas serán el castellano, el inglés, el portugués y el neerlandés." (TRATADO CONSTITUTIVO, 2011, p. 26). En el Reglamento General del mismo organismo, firmado el 11 de junio 2012, en Bogotá (Colombia), los Artículos 64 y 65 del 'Capítulo VIII: Organización de reuniones' presentan el término 'idiomas de trabajo', diferenciándolo del término 'idiomas oficiales’ al cual se hizo referencia en el tratado anterior:

Artículo 64

Sin perjuicio de lo señalado en el Artículo 23 del Tratado Constitutivo, los idiomas de trabajo de UNASUR son el castellano y el inglés. Las reuniones de los órganos y demás instancias de

1. (...) tal medida atua, tanto simbólica, como objetivamente, no não reconhecimento da "estrangeiridade" do idioma espanhol para o falante de português e vice-versa, ao tirar o prestígio e, consequentemente, diminuir o status do idioma no âmbito da tradução, ao trazer também à tona a questão da suposta facilidade de compreensão da língua espanhola pelos brasileiros, estereótipo bastante difundido no Brasil, sobretudo nas regiões sul e sudeste do país. 
UNASUR, serán conducidas en dichos idiomas de trabajo, a excepción de las reuniones del Consejo de Jefas y Jefes de Estado y de Gobierno, de Ministras y Ministros de Relaciones Exteriores y las reuniones ministeriales de los Consejos de UNASUR que contarán con interpretación en los cuatro idiomas oficiales de UNASUR. (REGLAMENTO GENERAL, 2012, p. 67 , subrayados nuestros).

\section{Artículo 65}

La Secretaría General redactará, en los idiomas de trabajo, el proyecto de informe de las reuniones de UNASUR. (...).

Serán elaborados en los cuatro idiomas oficiales los instrumentos jurídicos adicionales al Tratado Constitutivo, los Acuerdos que celebren los Estados Miembros de UNASUR sobre la base del Tratado Constitutivo, las Decisiones del Consejo de Jefas y Jefes de Estado, las Resoluciones del Consejo de Ministras y Ministros de Relaciones Exteriores y las Declaraciones de las reuniones de nivel ministerial de los Consejos de UNASUR. (REGLAMENTO GENERAL, 2012, pp. 67-68, subrayados nuestros).

Solo se menciona la traducción en el 'Capítulo IX: Sistematización de Actos Normativosy Documentos', en el Artículo 70, intitulado 'Actos normativos aprobados' y el Artículo 71, intitulado 'Traducción y circulación de los actos normativos'. En el primero, se especifica que "Los actos normativos que sean aprobados en cualquier reunión de UNASUR, deberán ser rubricados por los representantes de los países en los idiomas en que se redactaron", o sea, en los idiomas de trabajo, "para su ulterior traducción a los demás idiomas oficiales" (REGLAMENTO GENERAL, 2012, p. 69), susceptible de aprobación. En el Artículo 71, al proyecto debidamente aprobado en los idiomas de trabajo, "La Secretaría General proporcionará su traducción en los cuatro idiomas oficiales de UNASUR y circulará la versión autenticada del acto normativo." (REGLAMENTO GENERAL, 2012, p. 70).

De hecho, lo que se interpreta de este tratado es la predominancia oral de los idiomas de trabajo en las reuniones, como en los casos en que se requiere interpretación, y escrita en las consagraciones de los documentos, salvo pocos casos mencionados. La presencia de la traducción es ulterior, o sea, los documentos por firmarse también se redactan en español e inglés.

Con estos breves apuntes, nos gustaría subrayar el gusto y el interés de los brasileros por aprender lengua española, comprender e involucrarse con la diversidad de las culturas de los países de habla hispana de Latinoamérica y, además, consumir los productos culturales oriundos de estos países, no hay como alejarlos de los estereotipos, tales como investigados por Simão (2011), reforzados por la manera que los gobiernos legitiman (o no) una lengua en detrimento de otra y conducen la relación entre el español y el portugués. En realidad, según Bourdieu (2014),

Cualquier dominación simbólica implica, por parte de los que la sufren, una especie de complicidad que no es sumisión pasiva a una norma externa ni adhesión libre a valores. El reconocimiento de la legitimidad de la lengua oficial no tiene nada que ver con una creencia 
profesada expresamente, deliberada y revocable, ni con un acto de intenciones de aceptación de una 'norma'; se inscribe, en la práctica, en las disposiciones que se inculcan poco a poco, a través de un proceso de adquisición largo y lento, mediante las sanciones del mercado lingüístico y que se encuentran de este modo ajustadas (...). (BOURDIEU, 2014, pp. 29-30).

A seguir, intentaremos demostrarles cómo las publicaciones de historietas traducidas en Brasil, un producto cultural muy consumido, avanzan entre embates mercadológicos semejantes a los impuestos por las estructuras gubernamentales y cómo, en alguna medida, hay agentes que se proponen desestructurar estos órdenes, convirtiéndolos en otros espacios de dominación o alteridad.

\section{LAS PUBLICACIONES DE HISTORIETAS TRADUCIDAS EN BRASIL Y SUS TERRITORIOS}

En Brasil, para que se comprenda el mercado editorial de historietas, debemos concentrar en las traducciones publicadas, las responsables por impulsar el mercado desde el inicio del siglo XIX, una vez que esa literatura -aquí comprendida como un "fenómeno de la civilización" que "depende, para constituirse y caracterizarse, del entrelazamiento de diversos factores sociales" (CÂNDIDO, 2006, p. 20)-, se consideraba establecida, al tiempo que las publicaciones de historietas nacionales todavía integraban un proceso de cristalización de este hipergénero (RAMOS, 2007). Así que se puede decir que las traducciones de historietas tomaron la posición central en este polisistema literario (EVEN-ZOHAR 1990 [1978], pp. 193-194).

Seguramente, el posicionamiento de investigadores y escritores se mostró fundamental para convertir las historietas en objetos reconocibles en el campo de producción cultural, de entretenimiento (a través de publicaciones periodísticas y la realización de exhibiciones sobre el tema), y académico (a través de la publicación de libros, tesinas y tesis, además de realizar grupos de investigación, asociaciones, congresos etc.), especialmente después de los años 1950. Sin embargo, fue sobre todo a través del acceso a los títulos extranjeros, publicados en los más diversos soportes que los lectores brasileros conocieron el hipergénero $y_{\text {, cautivados, }}$ integraron este universo, como atestigua José Marques de Melo, uno de los pioneros en la investigación de historietas en Brasil, a través del relato de su experiencia:

Mi generación se educó bajo el signo del cómic. (...) Contaminado por la 'comicmanía', una especie de eufonía comunitaria que alcanzaba lectores, coleccionistas y aficionados, yo asimilaba naturalmente los tipos del legendario yanqui: Mandrake, Tarzan, Buck Jones, Roy Rogers, Flash Gordon, Superman. Pero también incorporé los cómics abrasilerados, tales 
como Trifón, Sisebuta, Carozo Pimienta, Tobi Tapia, La pequeña Lulú. ${ }^{2}$ (VERGUEIRO et al., 2013, p. 12, traducción nuestra).

No se puede, sin embargo, relacionar directamente el interés por la publicación y lectura de historietas extranjeras a un desfasaje en los modos de producción nacionales. Al contrario, la publicación brasilera no estuvo por debajo de las tendencias de creación historietista mundial en el fin del siglo XIX. Tras sesenta años de la llegada de la prensa tipográfica y, por consecuencia, del inicio de la prensa en Rio de Janeiro en 1808, se publicó en las páginas de la revista Vida Fluminense (1869) la primera historieta brasilera As Aventuras de Nbô Quim -como así lo defiende Moacy Cirne (1990), otro de los pioneros- creada por el ítalo-brasilero Angelo Agostini. Aun así, la traducción se destaca en estos primeros bocetos de mercado, por ejemplo, en la revista O Tico-Tico, publicada en 1905, la primera becha solamente con historietas y con historietas traducidas de Richard F. Outcault, uno de los íconos del cómic estadunidenses de aquel entonces.

Otro factor histórico digno de relieve y que nos invita a pensar el papel de la traducción y la influencia de los cómics estadunidenses en el mercado editorial nacional -y quizás, a través de relaciones comerciales semejantes, se puede decir de una influencia en el mercado editorial latinoamericano- es el viaje del joven editor Adolfo Aizen a los Estados Unidos en los años 1930. Observando la influencia de los cómics en el aumento de las ventas de los periódicos y revistas, Aizen contactó directamente a los distribuidores de los syndicates (gestores/agentes de cómics y materiales de entretenimiento) y empezó a publicar dichos contenidos en Brasil por la Editorial Brasil-América Limitada (EBAL), una de las más importantes del país (JUNIOR, 2004). Desde entonces, tal hecho fue determinante para ceñir la relación entre las publicaciones de historietas estadunidenses y sus traducciones al portugués brasilero.

En efecto, las publicaciones extranjeras predominan en el país desde el siglo XX, como afirman las investigaciones de José Marques de Melo (1970) y Paulo Ramos (2008), las cuales se propusieron investigar, entre otros datos, el porcentaje de historietas publicadas en los quioscos de diarios brasileros entre los meses de agosto y noviembre de 1967 y 2007, respectivamente. En la primera, se identificó

2. Minha geração educou-se sob o signo do gibi. [...] Contaminado pela gibimania, uma espécie de eufonia comunitária que atingia leitores, colecionadores e amadores, fui assimilando naturalmente as figuras do lendário ianque: Mandrake, Tarzan, Buck Jones, Roy Rogers, Flash Gordon, Superman. Mas incorporei também as que foram abrasileiradas, como Pafúncio, Marocas, Pinduca, Bolinha, Luluzinha. 
que el $70 \%$ de los títulos de historietas publicadas regularmente se trataba de materiales extranjeros, sobre todo oriundos de Estados Unidos e Italia.

Cuarenta años después, a fin de actualizar los datos colectados por Marques de Melo (1970), Paulo Ramos (2008) adoptó una metodología semejante e identificó un aumento de las revistas de historietas: el $84,1 \%$ se trataba, en su mayoría, de historietas de Estados Unidos y Japón; y el 15,9\% restante representaba las publicaciones nacionales, cuyo contenido se dedicaba al público infantil y en el que se observa la influencia del molde extranjero en la factura de las historietas nacionales.

La novedad se muestra con relación a las publicaciones japonesas. Los mangas alumbran como tema de interés de investigadores brasileros desde los años 1970, con la influencia de la investigadora Sonia Bibe Luyten, la responsable por la primera edición de la revista Quadreca y de la creación de la Associação Brasileira de amigos de Mangá e Ilustração (Abrademi) (VERGUEIRO et al., 2013, pp. 4854). En esta época, ciertos títulos de mangas vinieron en navío de Japón a Brasil, y llegaban con tres meses de retraso, según relata la traductora Drik Sada (2017). Las primeras traducciones al portugués fechan en la década de 1990, pero se las hacían a partir de títulos traducidos del inglés o francés. Las traducciones directas del japonés al portugués son de los años 2000, publicadas principalmente por las editoriales Conrad, Panini y JBC.

En la búsqueda por traductores de japonés, me parece que ellos [los editores] han tenido dificultades para encontrar profesionales disponibles, pues, tanto en aquella época como hoy, son muchos los hablantes de japonés, pero no todos ellos tienen una escritura satisfactoria; $y_{\text {, }}$ además, los que escriben bien no siempre tienen un japonés suficiente para interpretar matices culturales. ${ }^{3}$ (SADA, 2017).

Drik Sada empezó su carrera traduciendo la serie Dragon Ball, a partir del Volumen 9 de la edición brasilera (lo equivalente al volumen 5 de la japonesa), y sigue trabajando como traductora de mangas desde entonces, tanto de títulos infantojuveniles (Shounen e Shoujo) como de adultos (Seinen). Según Sada (2017), les interesa más a las editoriales brasileras publicar títulos vinculados a los temas de aventuras y luchas, por la influencia de los dibujos animados, tales como Dragon Ball (publicados por las editoriales Conrad y Panini), Bleach y Naruto (publicados por

3. Na busca de tradutores de japonês, acredito que eles [os editores] tenham tido dificuldade de encontrar profissionais disponíveis, pois, tanto naquela época como hoje, são muitos os que falam japonês, mas nem todos têm boa redação, e os que escrevem bem, nem sempre têm o japonês suficiente para interpretar nuances culturais. 
Panini), sin embargo en Japón hay muchos títulos todavía no explorados por las editoriales brasileras.

\section{LAS HISTORIETAS LATINOAMERICANAS EN BRASIL}

Con respecto a la publicación de historietas argentinas en Brasil en las décadas de los 1920 y 1930, ni siquiera los eficientes métodos de distribución semejantes a los syndicates, tal cual el creado por el historietista Dante Quinterno, permitieron que la traducción del famosísimo personaje indio Patoruzú llegara al país.

La primera aparición del personaje en Argentina ocurrió en el periódico Crítica en 1928, en las tiras cómicas Aventuras de Don Gil Contento -intituladas anteriormente de Un porteño optimista-, bajo el nombre Curugua-Curiguagüigua, que todavía tenía un papel secundario. En 1931, Patoruzú conquistó sus propias tiras, primero publicadas en La Razón e incorporadas después al periódico El Mundo, de la Editorial Haynes, en 1935 (GIUNTA, 2015). Ambicionado por publicar y distribuir sus propias revistas de manera independiente, Quinterno creó su editorial Casa Editorial Dante Quinterno S.A. en 1936, la cual se convirtió en una de las más relevantes del mercado editorial argentino, publicando 300.000 mil ejemplares, semanalmente, de la revista Patoruzú (SANTOS, 2016, p. 8) y manteniéndose activa hasta abril de 1977. La notoriedad del personaje llegó a los Estados Unidos el 25 de agosto de 1941, con las historietas The adventures of Patoruzú ; traducidas al inglés y publicadas en el periódico PM, de Nueva York -creado en 1940 y de inclinaciones más liberales-y por allí se mantuvo hasta 1948, con el cierre de la editorial del periódico. Esa fue la primera historieta argentina publicada en el extranjero (GIUNTA, 2015).

Las investigaciones de Paulo Ramos, una de las más importantes cuando se trata del lenguaje de las historietas, demuestran la escasez de publicaciones de historietas argentinas en Brasil hasta los años 2000 en el Blog dos Quadrinhos', desde 2008, y en el libro Bienvenido: um passeio pelos quadrinhos argentinos, desde 2016. Curiosamente, las historietas más traducidas y publicadas en Brasil son de los personajes que llevan la letra inicial " $\mathrm{M}$ " en sus nombres y que intitulan dichas publicaciones: Mafalda, de Joaquín Salvador Lavado (Quino), publicadas en soporte álbum por la editorial Martins Fontes desde 1991, cuyas traducciones las coordinó Monica Stahel; Mulheres Alteradas, de Maitena Burundarena, publicadas en el periódico Folba de S. Paulo y en la revista Claudia entre 2003 y 2008, y en soporte álbum $(26$ x 18,5 cm) por la editorial

4. Blog dos Quadrinbos. Disponible en: <http://blogdosquadrinhos.blog.uol.com.br/>. Accesado en: dic. 2017. 
Rocco en 2003, traducidas por Ryta Vinagre; y Macanudo, de Ricardo Liniers Siri, publicadas por la editorial Zarabatana Books en soporte libreto $(20,8 \times 20,4 \mathrm{~cm})$ desde 2008, traducidas por Claudio R. Martini, fundador de la editoral.

Así que, dibujantes más 'marginales' como Copi (Raúl Damonte Taborda, 1939-1987), que tal cual Quino colaboró en las revistas Tía Vicenta, en los años 1950, y en Cuatro Patas, a comienzos de los años 1960, además de publicar en Francia, donde se radicó en 1962, lanzando por allí el personaje La Mujer Sentada, tampoco llegaron a Brasil.

Otro caso interesante para ilustrar esa precariedad de traducciones de historietas latinoamericanas en Brasil es la reciente publicación de El Eternauta (O Eternauta, en portugués). Producidas inicialmente en los fines de la década de 1950 en suplementos semanales y compiladas en soporte libro a partir de 1993. Estas historietas, clásicas en argentina, escritas por Héctor G. Oesterheld (guion) y dibujadas por Francisco Solano López (arte) se tradujeron al portugués solamente en los años 2011 (O Eternauta) y 2013 (O Eternauta II), realizadas por Sergio Molina y Rubia Prates Goldoni, publicadas por la editorial Martins Editora Livraria. Lo curioso es que el traductor Sergio Molina también es el traductor de las célebres obras El ingenioso bidalgo don Quijote de la Mancha (O engenhoso fidalgo D. Quixote de La Mancha), Tomo I y II, publicadas por la Editora 34 en 2002 y 2007, respectivamente; y en este caso creemos que haya un intento editorial de atribuir prestigio a las historietas, ya sea por la experiencia del traductor, considerado uno de los más actuantes cuando se trata de traducciones literarias, ya sea porque la editorial no tiene la tradición de publicar historietas y no quiere arriesgarse en el mercado con una traducción desconocida.

Si las historietas argentinas tardaron en llegar a Brasil, las traducciones de historietas peruanas, por su parte, con menos estabilidad y tradición, tienen muy pocos representantes. Por aquí se conoce el clásico Para bacer bistorietas (Editorial Popular, 1981) de Juan Acevedo, intitulado Como fazer histórias em quadrinhos y traducido por Sílvio Neves Ferreira (Editorial Global, 1990), un libro teórico que introduce conceptos relevantes para los que desean comprender el lenguaje de las historietas. Y además se conocen los trabajos de los historietistas Pablo Marcos, Gonzalo Mayo y Boris Vallejo por sus dibujos en portadas de títulos famosos publicados en Estados Unidos, tales como Conan el Bárbaro (de Robert E. Howard, 1932), Vampirella (de Forrest J Ackerman y Trina Robbins, 1969) y Batman (de Bob Kane y Bill Finger, 1939), porque, al fin, en el mundo de la industria editorial, São Paulo está más cerca de Nueva York que de Lima (CAMPOS, 2016, p. 9). En 2016, la editorial Veneta fue pionera traduciendo y publicando en el libro Sendero Luminoso dos novelas 
gráficas peruanas, que destacaré más adelante: Rupay. Historias gráficas de la violencia política en el Perú (1980-1984), de Luis Rossell, Alfredo Villar y Jesús Cossio (Editorial Contracultura, 2008), y Barbarie. Comics sobre Violencia Política en el Perú, 1985-1990, de Jesús Cossio (Editorial Contracultura, 2010).

En este aspecto, editoriales brasileras independientes, tales como Veneta, fundada en 2012 por Rogério de Campos, y Zarabatana Books, fundada en 2006 por Claudio R. Martini, además de tiendas que se dedican a la comercialización de publicaciones independientes de historietas, adquieren un papel importante en esta industria; observando la multiplicidad de lo que ofrece el mercado latinoamericano, introducen nuevos títulos (y culturas) en el ideario nacional, reforzando el intercambio entre las fronteras. Algunos historietistas independientes brasileros, por su parte, también contribuyen en este intercambio cultural en sus creaciones, utilizando el contexto político y conflictivo de Latinoamérica como tema narrativo, como por ejemplo la obra Por mais um dia com Zapata (2015), de Daniel Esteves (guion), Al Stefano y Alex Rodrigues (arte y portada), publicada a través del sello independiente Zapata Edições (2013).

\section{CULTURA DE DISTRIBUCIÓN, CULTURA DE CONSUMO}

Aunque se conviene plantear la distribución de los libros (productos) como uno de los problemas más significantes que recaen sobre el mercado librero del siglo XXI en Brasil, observamos que no se trata de un obstáculo nuevo. Hallewell (2012, p. 358) registra que desde 1910 Monteiro Lobato (1882-1948), uno de los más influyentes escritores de literatura infantil brasilera del siglo XX, se había dado cuenta de la escasez de los puntos de ventas en el país y desarrolló una red de distribución denominada Revista do Brasil, con alrededor de dos mil distribuidores esparcidos entre tiendas, droguerías, panaderías etc.

En los años 1970, había la importante figura del librero, que intermediaba el vínculo entre las librerías y el público, circulando por las plazas y ciudades del interior del país, y todavía utilizaba el modelo de Lobato, ofreciendo los libros en expositores localizados en tiendas, peluquerías, cadena de supermercados, gasolineras y, además, en los taxis de la capital São Paulo, como señaló el escritor Carlos Drummond de Andrade en la crónica Compre livro no táxi, publicada en el suplemento Caderno B del periódico Jornal do Brasil (ZOCAL, 2015, pp. 75-77).

Enquanto no Rio os motoristas de praça ainda cuidam de adaptar os taxímetros à nova tabela periódica de preços, os seus colegas de São Paulo já vão de primeira na corrida cultural, uma corrida diferente de qualquer outra. Junto à direção, os carros ostentam pequena e variada coleção de livros. Novidade de uma empresa de transportes coletivos. 
- O senhor gosta de ler tanto assim nas horas de folga? - pergunta o passageiro, que nunca vira livro algum em táxi, salvo aquele que alguém esquecera, de propósito, para livrar-se de um poeta-processo.

- Gostar eu gosto, doutor, mas é que nunca tenho folga.

- Então por que carrega esses livros todos no carro?

- Para vender. (ANDRADE, 2013, pp. 17-19) 5

En la actualidad de los años 2017, se observan en São Paulo grandes agrupamientos de ferias independientes de y sobre historietas, donde se pueden promover y vender los diversos productos (historietas, fanzines, camisetas, figuras de acción etc.). Si bien observamos una imponencia de las grandes redes libreras, tales como Livraria Cultura y Saraiva, la cultura independiente creó su propio espacio y vinculaciones con un público específico, no estableciendo, de esa manera, una competencia real con las grandes librerías.

Además, no podemos desconsiderar el importante papel que las tecnologías digitales han ejercido en la comunicación y en la coyuntura histórica desde la mitad del siglo XX. Aunque no podemos mensurar en datos cuantitativos todavía cuanto los medios digitales han estimulado el consumo de las publicaciones de historietas en Brasil, por lo menos, podemos afirmar que ellas contribuyen en el intercambio de informaciones con respecto a lo que se produce (o se produjo) en determinado país, fomentando la lectura y el consumo de historietas disponibles en papel u online. Se habla más sobre las historietas en blogs, revistas y periódicos online, y se puede consumir más historietas desde cualquier parte del mundo a través del acceso a internet, pues en los sitios de las editoriales se permite al usuario adquirir los productos.

Por lo visto, la distribución y la publicidad no son más los problemas centrales del mercado editorial de historietas, cuyo eje, según nos parece, recae actualmente sobre el valor del producto. Teniendo en cuenta que el mayor efecto de la cultura, si pensada transversalmente, es la concientización de las personas a partir de una política integral (YÚDICE, 2006), tal contexto nos hace cuestionar

5. Mientras que en Rio los conductores todavía se encargan de adaptar los taxímetros a la nueva tabla periódica de precios, sus colegas de São Paulo ya van de primera a la carrera cultural, una carrera distinta a cualquiera. Junto a la dirección, los coches ostentan pequeña y variada colección de libros. Novedad de una empresa de transportes colectivos.

- ¿A usted le gusta tanto leer en sus momentos de ocio? - pregunta el pasajero, que nunca viera un libro en un taxi, excepto que alguien lo haya olvidado, a propósito, para librarse de un poeta procesual.

- Sí, me gusta, señor, pero nunca tengo descanso.

- ¿Y entonces por qué carga todos estos libros en su coche?

- Para vender. (ANDRADE, 2013, pp. 17-19, traducción de Pablo Moronta). 
si el hecho de que se publican más historietas latinoamericanas en los últimos años es una motivación suficiente para exceder las fronteras de intercambio cultural. Además, ¿́para quién están disponibles estos productos en Brasil?, chasta dónde llegan los bordes de la frontera del mercado?, chasta lo que se conviene denominar 'las masas'? Apuntamos tales cuestiones conscientes de que todavía sus respuestas van a ser tratadas con más detalles oportunamente en las investigaciones futuras.

\section{EL TRADUCTOR: AGENTE Y MEDIADOR DE CULTURAS}

Desde la traducción hasta la publicación de un libro traducido hay una diversidad de agentes normalizadores a lo largo de la cadena de producción, responsables por el producto final que llega efectivamente al público; son los traductores, correctores, rotulista, diagramadores, que están susceptibles, en distintas proporciones, de seguir las normas de las editoriales (BAGNO, 2017, pp. 172-173). Observamos, con todo, otros tantos profesionales que se encargan de los procedimientos anteriores a la traducción, pero que influencian sobre manera la factura de dicha traducción: los agentes se ocupan de la compra de los derechos de autor, los editores locales y de la traducción mantienen un intercambio para recibir las imágenes en alta definición etc.

Con el aumento de las editoriales independientes, el oficio que se atribuía a distintos profesionales pasa a ser realizado por solamente un agente. Este es el caso de muchos traductores en la actualidad que, actuando como mediadores culturales más allá de las relaciones textuales e icónicas, trabajan como editores, agentes de derechos o, incluso, son los propios propietarios de las editoriales. En este último caso, puntuamos el importante papel que agregan los propietarios-traductores en el juego de las relaciones del mercado de historietas independientes, pues eligen los textos e imágenes a traducir construyendo realidades y, además, disponen del poder del lenguaje aplicándolo en la traducción propiamente dicha. Mencionamos anteriormente el ejemplo de Rogério de Campos (Editorial Veneta), al que volvemos para analizar brevemente algunos aspectos del proceso de legitimación de la historieta traducida Sendero Luminoso (2016) en Brasil.

\section{SENDERO LUMINOSO, UN ESTUDIO DE CASO}

En el prefacio de Rupay (2008), los autores declaran cómo les gustaría que esta historieta contribuyera como resistencia de la memoria popular. En ella, ellos abordan los años dolorosos de conflictos armados entre los peruanos (paisanos, 
militares y los guerrilleros de Sendero Luminoso) entre 1980 y 1984, e intentan reconstruir esa historia narrándola por imágenes, fotografías y fragmentos de los periódicos de la época bajo la óptica del pueblo peruano.

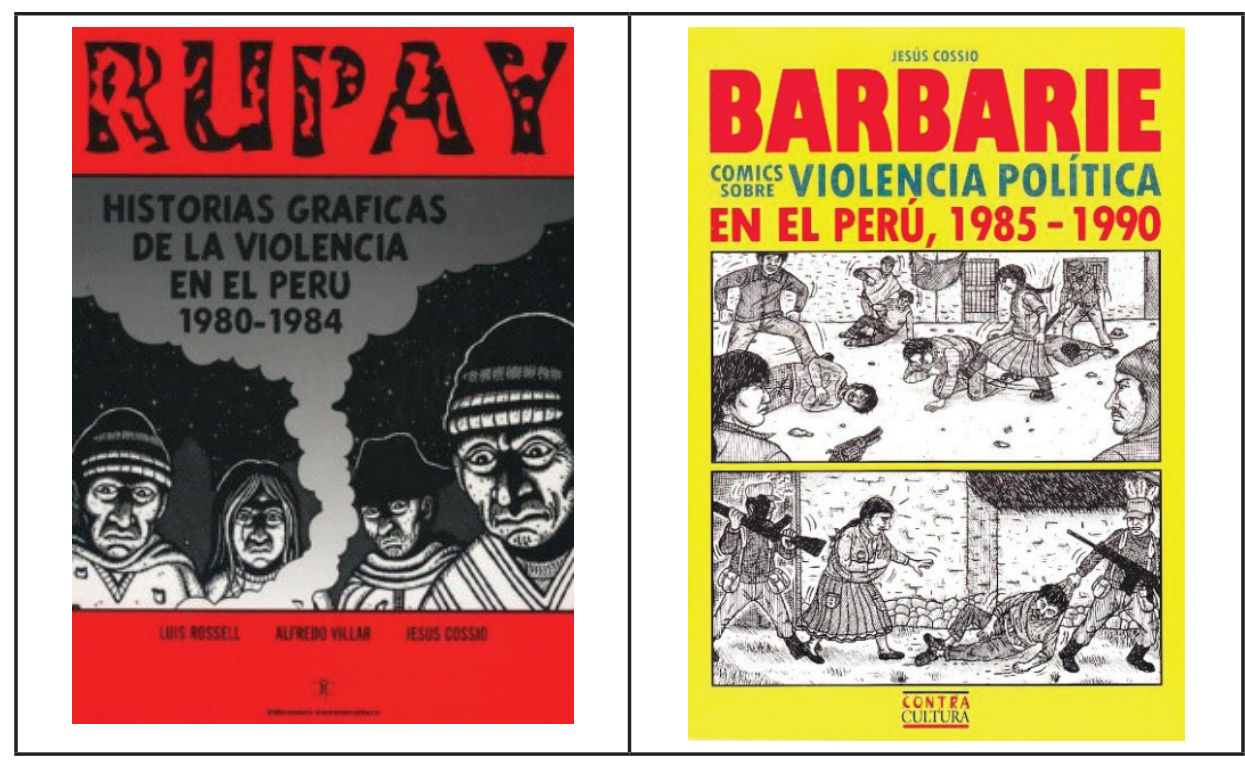

Figura 1. Rupay. Historias gráficas de la violencia política en el Perú (1980-1984). Fuente: VILLAR; ROSSELL; COSSIO, 2008.
Figura 2. Barbarie. Comics sobre Violencia Política en el Perú, 1985-1990.

Fuente: COSSIO, 2010.

Aquí no hay verdades absolutas sino el intento de comenzar a discutir todos los mitos que se han construido alrededor de esas verdades absolutas, sean las de unos u otros. Es una invitación a 'pasarle a la historia el cepillo a contrapelo', a cuestionar dogmas y abrir polémicas, a romper el silencio y quebrar la enajenación del olvido, a crear otras miradas y documentos. (VILLAR, ROSSELL; COSSIO, 2008)

El título Rupay (Figura 1), designa tanto "Solazo, fenómeno meteorológico que produce el Sol con su luz y calor durante el día" como "Quemar, incinerar, abrasar el fuego" (DICCIONARIO QUECHUA, 2005, p. 172). Recuperando esta palabra quechua, intuimos que los autores ponen en evidencia, desde el título, lo regional, lo ancestral, los indígenas que vivían en las regiones del conflicto (posteriormente, en el curso de la historia, demostrado y clasificado como una barbarie), que lucharon para defender los suyos y que, al fin y al cabo, se convirtieron en las principales

6. El Diccionario Quechua - Español-Quechua (2005, p. 172) presenta la grafía 'ruphay', con 'h'. 
víctimas. Tanto el poder del Estado peruano como el de los senderistas se revolcaron en contra del pueblo autóctono.

Así también evidencia la imagen de la portada, cuyo enfoque está en los sentimientos de los ayacuchanos: la disposición de los personajes en círculo, alrededor de la humareda, remite a encuentros tradicionales, así como sus trajes; las rayas y marcas de expresión en sus rostros indican preocupación. Los colores sobresalen en matices de blanco, negro y gris, y el rojo vibrante se destaca sobre y abajo de ellos. En el interior de la historieta, los esparcidos rojos salpican las escenas de extrema violencia.

En Barbarie (2010) (Figura 2), también observamos una simbiosis entre el título y la portada. Se trata de una historieta posterior a Rupay (2008), que registra la lucha entre los años 1985 y 1990, en la cual Jesús Cossio trabaja solo y trasparece su estilo propio: trazos muy marcados, sobre todo por los sombreados, y, tal cual sugiere el nombre, registran muchas más escenas de violencia. Los colores calientes, el amarillo en contraste con el rojo, la imagen de una chica al centro de las dos escenas, las armas de fuego y las luchas corporales solo confirman la puesta en relieve a la violencia de los años clímax del conflicto, explotadas sobre todo en el dibujo, pues, al contrario de Rupay, donde se intercalaba dibujos, fotografías (alrededor de 22) y reportajes, en Barbarie no hay ninguna fotografía y tampoco escenas que exploran los recursos del color rojo.

Percibimos también una distinción en la segunda parte de los títulos de los dos volúmenes. Mientras se clasifica a Rupay como 'historia gráfica', al segundo se lo clasifica como 'cómics'. Sin embargo, no vamos a detenernos en estas clasificaciones en este momento, porque si volvemos a la traducción brasilera, ella ya se muestra bastante compleja.

Uno de los aspectos es el proyecto gráfico de la traducción en el que observamos los dos volúmenes que se convirtieron en uno (Figura 3 , a continuación). El otro es la traducción, intitulada Sendero Luminoso (2016), que pone en evidencia el grupo senderista, al contrario de lo que propusieron las historietas en español. Kaindl (2010, p. 38) observa que la elección de los títulos en las traducciones es influenciada sobre todo por factores de publicidad y económicos; además de ser una tendencia desde los años 1960 mantener los títulos en la lengua fuente (que, en este caso, sería el español), especialmente si incluyen los nombres de los protagonistas. Desde el prefacio, los autores nos aclaran que el enfoque de dichas historietas es la memoria popular y aunque los campesinos participaron y lidiaron las guerrillas, los podemos considerar las víctimas de esta barbarie. Sin embargo, atribuimos el título 
brasilero a un reflejo de la edición francesa (Figura 4, a continuación) intitulada 'Sentieux Lumineux' y publicada un año antes de la brasilera.

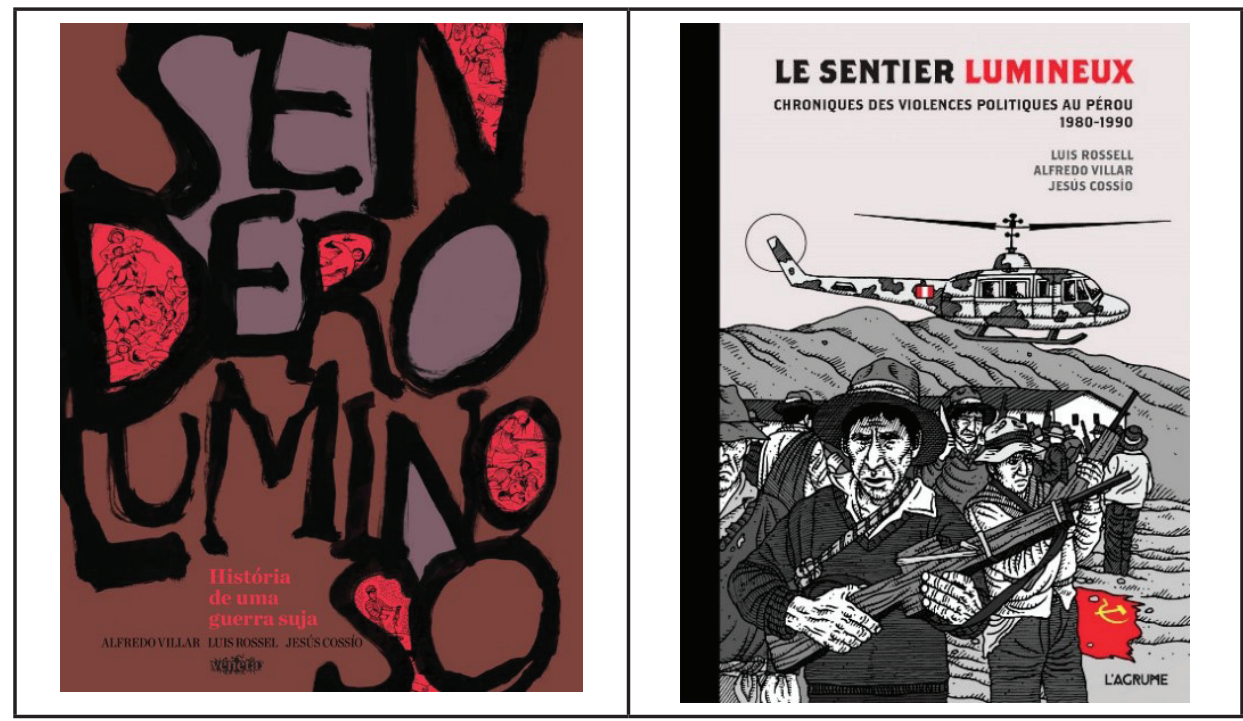

Figura 3. Sendero Luminoso. História de uma

Figura. 4. Le Sentieux Lumineux. Chroniques guerra suja. des violences politiques au Pérou 1980-1990. Fuente: VILLAR; ROSSELL; COSSIO, 2016. Fuente: VILLAR; ROSSELL; COSSIO, 2015.

Más allá de los problemas de exceptuarse la identidad cultural de los peruanos descendientes de quechuas, percibimos en la portada de la edición francesa un intento de poner evidencia en la violencia y, además, a la violencia causada por los senderistas, al contrario, la muestran a todo momento. Se eligió una imagen de la guerra, hay armas de fuego, personajes en acción o huyendo de los ataques del gobierno, ilustrados por el helicóptero. Los colores se asemejan más bien a los de Rupay, y se destacan en rojo parte del título 'Lumineux', la bandera de Perú y la bandera del Partido Comunista del Perú - Sendero Luminoso (PCP-SL).

En contrapartida, la portada de la edición brasilera apuesta en una paleta de colores más discreta y opaca, remitiendo sutilmente al rojo, y en las imágenes sobresalen los sentimientos de Rupay. A pesar del título recurrir a un grupo estigmatizado en la historia mundial, las imágenes conducen los lectores a una impresión de sufrimiento y fragilidad, quizás volviendo al sentido quechua del fuego ritualista, sagrado, sendero de calor y amor. 


\section{CONCLUSIÓN}

Procuramos demostrar el papel fundamental de la traducción en la difusión de las historietas en Brasil y sobre todo las relaciones imbricadas en la tracción de historietas latinoamericanas al portugués brasilero. Valiéndonos de los abordajes sociológicos en los cuales se ancla nuestra investigación (BOURDIEU, 2014; WOLF; FUKARI, 2007 y PARADA; FOUCES, 2006), tampoco hemos podido ignorar las relaciones entre el producto libro, publicado en papel, y la internet, el principal vehículo de información y comunicación de la actualidad, que incluso molda las relaciones sociales más cotidianas.

Teniendo en cuenta que "la lengua legítima no comporta en sí el poder de garantizar su perpetuación en el tiempo como tampoco el de definir su extensión en el espacio" (BOURDIEU, 2014, p. 39), nuestra investigación se propuso evidenciar los juegos de poder desarrollados y los agentes involucrados en el seno del mercado editorial de las historietas. Nuestro objetivo no es otro que aclarar el monopolio del mercado extranjero estadunidense construido hace más de dos siglos en Brasil e inscribir una posibilidad de ascenso del mercado latinoamericano, construyendo un modo de expresión legítimo. Si no logramos huir de los modos de producción, intrínsecos al sistema económico actual, esperamos al menos reafirmar posibilidades de crear una efectiva competitividad de los mercados latinoamericanos de historietas en Brasil a través de la traducción, que ofrezca al público lector otros modelos de producción y consumo, una aproximación necesaria sobre todo en tiempos de crisis democráticas.

\section{REFERENCIAS BIBLIOGRÁFICAS}

ACEVEDO, J. (1978). Como fazer bistórias em quadrinbos. Trad. de Sílvio Neves Ferreira. São Paulo: Global, 1990.

ANDRADE, C. D. (2013). De notícias \& não notícias faz-se a crônica: Histórias - diálogos - divagações, $1^{\text {a }}$ ed. São Paulo: Cia. das Letras, p. 280.

BAGNO, M. (2017). Oralidade inverossímil e romance gráfico: a tradução brasileira de Aya de Yopougon. Translatio, $\mathrm{n}^{\mathrm{O}}$ 13, jul., pp.163-184.

BOURDIEU, P. (1999). La producción y la reproducción de la lengua legítima. In: ¿Qué significa bablar? Economía de los intercambios lingüísticos. Trad. de Esperanza Martínez Pérez. Madrid: Akal, pp. 19-48. 
CAMPOS, R. (2016). Prefácio da edição brasileira. In: VILLAR, A.; ROSSELL, L.; COSSIO, J. Sendero Luminoso. São Paulo: Veneta, pp. 5-10.

CÂNDIDO, A. (2006). Literatura e sociedade. Rio de Janeiro: Ouro sobre Azul.

COSSIO, J. (2010). Barbarie. Comics sobre Violencia Política en el Perú, 1985-1990. Buenos Aires: Editorial Contracultura.

DICCIONARIO QUECHUA - Español-Quechua. (2005). Perú: Academia Mayor de la Lengua Quechua. Qheswa Simi Hamut'ana Kurak Suntur.

EVEN-ZOHAR, I. (1978). The position on Translated Literature within the Literary Polysystem. In: VENUTI, L. (2000). The Translation Studies Reader. London, New York: Routledge, pp. 192-197.

GIUNTA, N. G. (2009). La bistoria del comic en la Argentina. Disponible en: <www. todohistorietas.com.ar/historia_argentina_1.htm >. Accesado en: jul. 2015.

HALLEWELL, L. (2012) O livro no Brasil: sua bistória. 3. ed. Trad. de Maria da Penha Villalobos, Lólio Lourenço de Oliveira e Geraldo Gerson de Souza. São Paulo: Edusp.

JUNIOR, G. (2004). A guerra dos gibis: a formação do mercado editorial brasileiro e a censura aos quadrinhos, 1933-64. São Paulo: Cia. das Letras.

KAINDL, K. (2010). Comics in translation. In: GAMBIER, Y.; DOORSLAER, L. (Eds.). Handbook of Translation Studies. Amsterdam/Philadelphia: John Benjamins, v. 1, pp. 3640.

MARQUES DE MELO, J. (1970). Quadrinhos no Brasil: estrutura industrial e conteúdo das mensagens. In: MARQUES DE MELO, J. Comunicação social: teoria e pesquisa. Petrópolis: Vozes, pp. 185-246.

PARADA, A.; FOUCES, O. (Eds.). (2006). Sociology of Translation. Vigo: Universidade de Vigo.

RAMOS, P. (2016). Bienvenido: um passeio pelos quadrinbos argentinos, $2^{\mathrm{a}}$ ed. Campinas: Zarabatana Books.

RAMOS, P. (2008). As mudanças no mercado de quadrinhos nos últimos 40 anos. In: VIII Encontro de Núcleos de Pesquisa em Comunicação. Natal (RN), setembro. 
RAMOS, P. (2007). Tiras cômicas e piadas: duas leituras, um efeito de bumor. Tese de Doutorado em Letras, Faculdade de Filosofia, Letras e Ciências Humanas, Universidade de São Paulo, São Paulo.

REGLAMENTO GENERAL de UNASUR. (2012). UNASUR/CTIRE, Bogotá. Disponible en: <https://www.unasursg.org/images/descargas/DOCUMENTOS\%20CONSTITUTIVOS\%20DE\%20UNASUR/reglamento_gral.pdf>. Accesado en: dic. 2017.

SADA, D. (2017). Questionários enviados por e-mail a autora, março.

SANTOS, C. do C. (2016). Uma tradução reflexiva da bistória em quadrinbos: Andanzas de Patoruzú - "Amor sin barreras". Trabalho de conclusão de curso de Bacharelado em Letras Tradução - Espanhol da Universidade de Brasília, Brasília. Disponible en: < http:// bdm.unb.br/handle/10483/17286>. Accesado en: dic. 2017.

SIMÃO, A. K. G. (2011). A dimensão estrangeira da tradução da língua espanhola no MERCOSUL. In-Traduções, v. 3, n. 4, pp. 49-58. Disponible en: < http://hdl.handle. net/11449/122601>. Accesado en: dic. 2017.

TRATADO CONSTITUTIVO de la Unión de Naciones Suramericanas. (2011). Secretaría General de UNASUR, Quito. Disponible en: < https://www.unasursg.org/images/ descargas/DOCUMENTOS\%20CONSTITUTIVOS\%20DE\%20UNASUR/ Tratado-UNASUR-solo.pdf>. Accesado en: dic. 2017.

VERGUEIRO, W.; SANTOS, R. E. (2006). A pesquisa sobre histórias em quadrinhos na Universidade de São Paulo: análise da produção de 1972 a 2005. UNIrevista, v. 1, n. 3.

VERGUEIRO, W.; SANTOS, R. E. (2014). As histórias em quadrinhos como objeto de estudo das teorias da comunicação. In: MARTINS, M. de L.; OLIVEIRA, M. O. (Eds.). Comunicação ibero-americana: os desafios da Internacionalização. Centro de Estudos de Comunicação e Sociedade, Universidade do Minho, pp. 4365-4380.

VERGUEIRO, W.; RAMOS, P.; CHINEN, N. (Orgs.). (2013). Os pioneiros nos estudos de quadrinbos no Brasil. São Paulo: Criativo.

VILLAR, A.; ROSSELL, L.; COSSIO, J. (2016). Sendero Luminoso. História de uma guerra suja. Trad. de Rogério de Campos e Barbara Zocal. São Paulo: Veneta.

VILLAR, A.; ROSSELL, L.; COSSIO, J. (2015). Le Sentier lumineux. Chroniques des violences politiques au Pérou 1980-1990. Trad. de Hélène Harry. Paris: L’Agrume. 
VILLAR, A.; ROSSELL, L.; COSSIO, J. (2008). Rupay. Historias gráficas de la violencia política en el Perú (1980-1984). Buenos Aires: Editorial Contracultura.

WOLF, M.; FUKARI, A. (eds.). (2007). Constructing a sociology of translation. Amsterdam/ Philadelphia: John Benjamins.

YÚDICE, G. (2006). ¿Unna o varias identidades? Cultura, globalización y migraciones. Nueva Sociedad, 201, enero - febrero, pp. 106-116. Disponible en: <http://nuso.org/ articulo/una-o-varias-identidades-cultura-globalizacion-y-migraciones/ $>$. Accesado en: dic. 2017.

ZOCAL, B. (2017). Traduzir Quadrinhos - Não há tradução mais fácil do que outra. A tradução e os tradutores no mercado editorial de histórias em quadrinhos. Metáfrase. n. 4, março, pp. 22-31.

ZOCAL, B. (2015). As tiras de Mafalda no Brasil: tradutores e traduções. Dissertação de Mestrado em Língua Espanhola e Literaturas Espanhola e Hispano-Americana da Faculdade de Filosofia, Letras e Ciências Humanas, Universidade de São Paulo, São Paulo.

Recebido: 13/02/2018

Aceito: 27/02/2018 